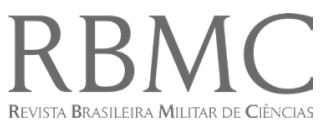

ISSN 2447-9071

doi https://doi.org/10.36414/rbmc.v6i15.43

Contato para correspondência:

Lucas Luiz de Lima Silva

E-mail:

limabiomed@hotmail.com

Conflito de interesse: Não

Financiamento: Recursos próprios

Recebido: 03/06/2020

Aprovado: 01/07/2020

\section{Uso de lactobacillus na erradicação de helicobacter pylori e na redução de reações adversas ao tratamento convencional: uma revisão integrativa}

\section{Use of lactobacillus to eradicate helicobacter pylori and reduce adverse reactions to treatment: an integrative review}

Luiza Segati de Amorim', Xisto Sena Passos'1, Antonio Márcio Teodoro Cordeiro Silva²,3, Juliana Menara de Souza Marques', Milton Camplesi Júnior', Ana Karoline Silva Oliveira4, Mônica Santiago Barbosa ${ }^{4}$, Lucas Luiz de Lima Silva ${ }^{1,4}$

1 Universidade Paulista - UNIP

${ }^{2}$ Pontifícia Universidade Católica de Goiás - PUC Goiás

${ }^{3}$ Faculdade da Polícia Militar - FPM

${ }^{4}$ Universidade Federal de Goiás - UFG

\section{Resumo}

O presente estudo teve como objetivo descrever e discutir sobre o uso de probióticos, de bactérias do gênero Lactobacillus, como complemento no tratamento da infecção por Helicobacter pylori (H. pylori) ena redução dos efeitos adversos do tratamento convencional. Trata-se de revisão integrativa da literatura, no qual os artigos foram acessados por meio das bases de dados BVS, Medline, PubMed e LILACS. Foram selecionados 16 artigos, publicados entre 2015 e 2019, todos em inglês. De acordo com a origem, dos 16 artigos selecionados, quatro eram da China (34\%), dois do Chile (12\%), dois da Alemanha (12\%), dois do Irã (12\%), eos seis restantes eram um de cadapaís, sendoestes:Egito, Irlanda, Itália, Japão, Tailândia e Taiwan, com a parcela de (5\%) para cada um. De acordo com sete estudos, as cepas: L. fermentum, L. acidophilus, L. rhamnosus, L. casei imunitass, L. gasseri (LG21), L. reuterie L. johnsonii (J88) são eficazes como complemento ao tratamento convencional da infecção por H. pylori. Adicionalmente, outros sete estudos indicaram melhora em sinais e sintomas, como:vômito, distúrbios do paladar, diarreia, distensão abdominal, constipação, náusea e inchaço. Há diversas evidências da eficácia do uso de Lactobacilos como probióticos na terapia convencional deerradicaçãoe na redução de reações adversas comuns ao tratamento de H. pylori.

Palavras-Chave: Bactéria; Probióticos; Suplementos Nutricionais.

\begin{abstract}
The present study aimed to describe and discuss the use of probiotics, of bacteria of the genus Lactobacillus, as a complement in the treatment of Helicobacter pylori (H. pylori) infection and in reducing the adverse effects of conventional treatment. This is an integrative literature review, in which the articles were accessed through the BVS, Medline, PubMed and LILACS databases. 16 articles were selected, published between 2015 and 2019, all in English. According to the origin, of the 16 selected articles, four were from China (34\%), two from Chile (12\%), two from Germany (12\%), two from Iran (12\%), and the remaining six were one each country, these being: Egypt, Ireland, Italy, Japan, Thailand and Taiwan, with a share of (5\%) for each. According to seven studies, the strains: L. fermentum, $L$. acidophilus, L. rhamnosus, L. casei immunitass, L. gasseri (LG21), L. reuteri and L. johnsonii (J88) are effective as a complement to conventional treatment $H$. pylori infection. In addition, seven otherstudies indicated improvement in signs and symptoms, such as vomiting, taste disorders, diarrhea, bloating, constipation, nausea and bloating. There is ample evidence of the effectiveness of using Lactobacilli
\end{abstract}


as probiotics in conventional eradication therapy and in reducing adverse reactions common to the treatment of H. pylori.

Keywords: Bacteria; Probiotics; Neutraceutical.

\section{Introdução}

Helicobacter pylori é uma bactéria gram negativa, de morfologia helicoidal, flagelada e microaerofília' e é considerada uma das causas de infecção mais comum em humanos. Estimase que mais da metade da população mundial está infectada pela bactéria ${ }^{2}$, que promove a sua colonização da mucosa gástrica, por meio da produção e secreção da enzima urease que neutraliza o ácido estomacal, elevando-o, por meio da hidrólise da ureia em dióxido de carbono e amônia ${ }^{3}$.

A infecção por H. pylori é fator de risco para diversas gastroduodenopatias, como: gastrite, úlcera, duodenite, esofagite, adenocarcinoma e linfoma de tecido linfoide associado à mucosa ${ }^{4}$. Alguns fatores, como saneamento básico, idade e local de residência, são significativos para a prevalência de $\mathrm{H}$. pylori em humanos ${ }^{3}$.

A resistência de cepas de $H$. pylori aos antibióticos utilizados em tratamentos convencionais, como claritromicina e amoxicilina, tem aumentado nos últimos anos. Os tratamentos convencionais com o uso de antibióticos e inibidor de bomba de próton $\mathbf{s}^{5}$, durante sete a quatorze dias, causam efeitos adversos, tais como: diarreia, náusea e vômito. Portanto, vem sendo considerada a busca de novas alternativas para o tratamento ${ }^{6,7}$.

A primeira definição sobre probióticos se deu em 1989, descritos como suplementos alimentares à base de microrganismos vivos, que afetam, beneficamente, o hospedeiro, promovendo o balanço de sua microbiota intestinal ${ }^{8}$. Em 2001, a Organização Mundial da Saúde alterou tal definição, agora descritos como microrganismos vivos, administrados em quantidades adequadas, que conferem benefícios à saúde do hospedeiro ${ }^{9}$. Um desses benefícios descritos é a melhora no equilíbrio da microbiota do trato digestório, como o aumento no número relativo de bactérias benéficas ${ }^{9,10}$. Existem alguns grupos de microrganismos que podem ser utilizados como probióticos, entre eles estão: as leveduras, como, por exemplo, Saccharomyces e as bactérias ${ }^{8}$. Entre as espécies de bactérias que podem ser utilizadas como microrganismos probióticos, estão Bifidobacterium e Lactobacillus, que são os dois gêneros de bactérias gram positivas comuns aplicados ao tratamento ${ }^{8,9}$. Além disso, são alternativa para uso em larga escala e de baixo custo ${ }^{11}$. Por esses motivos, vem sendo discutida, nos últimos anos, a possibilidade do uso de probióticos como alternativa para o tratamento complementar da infeção por H. pylori' ${ }^{12}$.
O presente estudo objetivou descrever e discutir o uso de probióticos, de bactérias do gênero Lactobacillus, como complemento no tratamento da infecção por Helicobacter pylori e na redução dos efeitos adversos do tratamento convencional.

\section{Métodos}

Trata-se de revisão integrativa de literatura. Essa modalidade de revisão permite avaliar dados de diversos estudos científicos, possibilitando a síntese e união de resultados gerais sobre um determinado tema, com a produção de novos conhecimentos sobre o assunto escolhido ${ }^{13}$.

Para elaboração de uma revisão integrativa é necessário executar as seguintes fases: determinação do tema e seleção da hipótese, definição do problema, formulação da pergunta de pesquisa, definição dos descritores e das bases de dados; estabelecimento dos critérios de inclusão e exclusão; constatação dos resultados pré-selecionados e selecionados; classificação dos estudos selecionados; análise e interpretação dos resultados, onde ocorre a discussão dos resultados de acordo com a análise realizada e a apresentação da síntese do conhecimento ${ }^{14}$.

Foram incluídos estudos que abordaram a temática sobre o uso de probióticos contendo Lactobacilos no tratamento do H. pylori por terapia convencional e as suas reações adversas, publicados entre 2015 e 2019, nos idiomas inglês, espanhol e português. Foram excluídos da busca efetuada, quaisquer monografias, teses, dissertações e manuais.

O levantamento bibliográfico foi realizado no site da Biblioteca Virtual em Saúde (BVS), na base de dados Medical Literature Analysis and Retrieval System Online (MEDLINE) e Literatura Latino-Americana e do Caribe em Ciências da Saúde (LILACS) e no site do National Center for Biotecnology Information (NCBI), na base de dados US National Library of Medicine (PubMed). Foram empregados, na busca, os seguintes Descritores de Ciências da Saúde (DeCS): H. pylori, Lactobacilos (Lactobacillus) e Probióticos (Probiotics).

Os descritores foram incluídos nas bases de dados selecionadas e as coletas de dados foram efetuadas por meio dos resultados encontrados. Os descritores foram agrupados com o boleando "AND", da seguinte forma: "H. pylori AND Lactobacillus" o que resultou em 600 artigos; "H. pylori AND probiotics", resultando em 616 artigos; "H. pylori AND probiotics 
AND Lactobacillus", retornando 350 artigos, totalizando 1.566 estudos. É importante acrescentar que utilizando as palavras em português Lactobacilos e probióticos não foram obtidos resultados para eles, alguns que apareceram já estavam nas pesquisas anteriores.

A seleção dos estudos foi iniciada com a escolha daqueles publicados nos últimos 5 anos, o que reduziu o montante para 575 estudos. A seleção secundaria se deu pela leitura dos títulos, onde artigos repetidos e que não correspondiam ao tema da pesquisa foram excluídos, restando 99 estudos. A seleção terciaria ocorreu pela leitura dos resumos, onde foram selecionados estudos que descreviam o uso de Lactobacilos na infecção por $H$. pylori, restando então 65 , é importante salientar que estudos onde foram utilizados probióticos de gêneros misturados, como por exemplo, Bifidobacterium aos Lactobacilos não foram selecionados. Nesta fase, os estudos foram lidos integralmente. Após a coleta dos dados, foram observadas as cepas de Lactobacilos que mais possuíam a capacidade de diminuir a taxa de erradicação, suas funções para essa redução em uso concomitante ao tratamento e como as reações adversas causadas pelo tratamento convencional eram minimizadas. O fluxograma metodológico está na Figura 1.

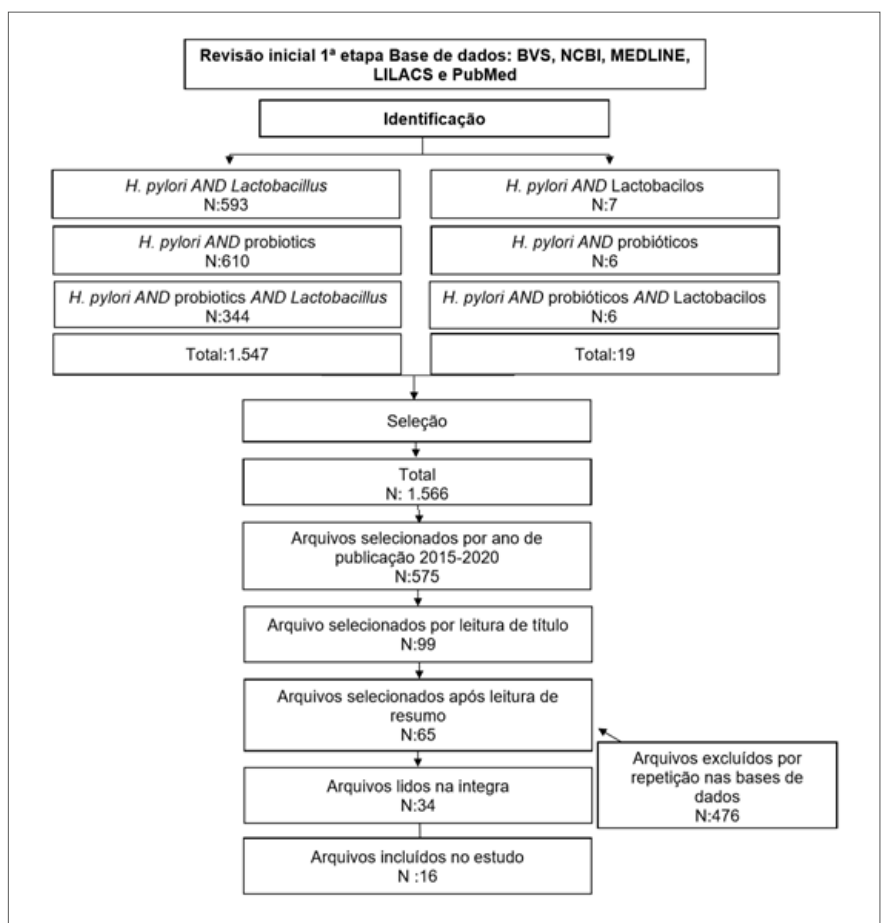

Figura 1. Fluxograma de identificação e seleção de artigos para revisão integrativa sobre o uso complementar de probióticos no tratamento da infecção por H. pylori. Fonte: dados de pesquisa.

\section{Resultados}

Foram 16 artigos selecionados para a confecção da presente revisão integrativa.

O Quadro 1 sumariza os dados dos 16 estudos selecionados.

Quadro 1. Dados dos 16 artigos selecionados para a presente revisão, publicados entre 2015 e 2020.

\begin{tabular}{|c|c|c|c|c|}
\hline Base de dados & Ano & Autores & Título & Conclusão \\
\hline Medline & 2015 & Holz et al. & $\begin{array}{l}\text { Significant Reduction in Helicobacter pylori Load in Hu- } \\
\text { mans with Non-viable Lactobacillus reuteri DSM17648: } \\
\text { A Pilot Study }\end{array}$ & $\begin{array}{l}\text { L. reuteri DSM17648 pode combater a resistência a anti- } \\
\text { bióticos nas infecções por H. pylori, por evitar o seu uso } \\
\text { e reduzir a carga de H. pylori ou curar doenças estoma- } \\
\text { cais induzidas pela infecção. }\end{array}$ \\
\hline Medline & 2015 & Paoluzi et al. & $\begin{array}{l}\text { Low efficacy of levofloxacin-doxycycline-based third- } \\
\text {-line triple therapy for Helicobacter pylori eradication } \\
\qquad \text { in Italy }\end{array}$ & $\begin{array}{l}\text { L. casei DG pode aumentar a probabilidade de sucesso e } \\
\text { tolerabilidade da terapia de erradicação do } \mathrm{H} \text {. pylori. }\end{array}$ \\
\hline Medline & 2015 & Enany; Abdalla & $\begin{array}{l}\text { In vitro antagonistic activity of Lactobacillus casei } \\
\text { against Helicobacter pylori }\end{array}$ & $\begin{array}{l}\text { L. casei inibiu o crescimento de cepas H. pylori e até de } \\
\text { cepas resistentes a antibióticos in vitro. }\end{array}$ \\
\hline PubMed & 2016 & Lü et al. & $\begin{array}{l}\text { Efficacy of Probiotic Supplementation Therapy for Heli- } \\
\text { cobacter pylori Eradication: A Meta-Analysis of Rando- } \\
\text { mized Controlled Trials. }\end{array}$ & $\begin{array}{l}\text { A suplementação de probióticos durante o tratamento } \\
\text { pode aumentar taxa de erradicação e diminuir a incidên- } \\
\text { cia de eventos adversos e sintomas gastrointestinais. }\end{array}$ \\
\hline LILACS & 2017 & García et al. & $\begin{array}{c}\text { Characterization of Lactobacillus fermentum UCO-979C, } \\
\text { a probiotic strain with a potent anti-Helicobacter pylori } \\
\text { activity. }\end{array}$ & $\begin{array}{l}\text { L. fermentum UCO- } 979 \text { C tolera as condições estomacais } \\
\text { e produz compostos antimicrobianos, além de modular } \\
\text { resposta imune inflamatória. }\end{array}$ \\
\hline PubMed & 2018 & Buckley et al. & $\begin{array}{l}\text { The effect of Lactobacillus reuteri supplementation } \\
\text { in Helicobacter pylori infection: a placebo-controlled, } \\
\text { single-blind study. }\end{array}$ & $\begin{array}{l}\text { L. reuteri DSM17648 tem o potencial o potencial de } \\
\text { suprimir infecção por H. pylori e pode levar a uma me- } \\
\text { Ihoria dos sintomas gastrointestinais associados. }\end{array}$ \\
\hline
\end{tabular}




\begin{tabular}{|c|c|c|c|c|}
\hline PubMed & 2018 & Ji et al. & $\begin{array}{l}\text { Efficacy of compound Lactobacillus acidophilus tablets } \\
\text { combined with quadruple therapy for Helicobacter } \\
\text { pylori eradication and its correlation with pH value in } \\
\text { the stomach: a study protocol of a randomised, assessor- } \\
\text { blinded, single-centre study. }\end{array}$ & $\begin{array}{l}\text { L. acidophilus como probiótico pode reduzir a secreção } \\
\text { de toxina bacteriana micropatogênica na superfície da } \\
\text { mucosa hospedeira, promover o reparo da mucosa e } \\
\text { ajudar a reduzir as reações adversas na terapia de erradi- } \\
\text { cação da H. pylori }\end{array}$ \\
\hline Medline & 2018 & Asgari et al. & $\begin{array}{c}\text { Honey-derived Lactobacillus rhamnosus alleviates } \\
\text { Helicobacter pylori-induced gastro-intestinal infection } \\
\text { and gastric inflammation in C57BL/6 mice: an immuno- } \\
\text {-histologic study. }\end{array}$ & $\begin{array}{l}\text { L. rhamnosus derivado do mel é tão eficaz quanto a } \\
\text { claritromicina na erradicação da infecção por H. pylori } \\
\text { e na cura da gastrite nos camundongos C57BL/6. }\end{array}$ \\
\hline PubMed & 2018 & $\begin{array}{l}\text { Gutiérrez-Za- } \\
\text { morano et al. }\end{array}$ & $\begin{array}{l}\text { Increased anti-Helicobacter pylori effect of the probio- } \\
\text { tic Lactobacillus fermentum UCO- } 979 \mathrm{C} \text { strain encapsu- } \\
\text { lated in carrageenan evaluated in gastric simulations } \\
\text { under fasting conditions }\end{array}$ & $\begin{array}{l}\text { L. fermentum UCO- } 979 \text { Cem um sistema gástrico } \\
\text { simulado comprova a atividade probiótica dessa cepa } \\
\text { previamente mostrada em estudos com modelos de } \\
\text { animais. Os resultados também mostraram que consu- } \\
\text { mir o probiótico, em condições de jejum, proporcionou } \\
\text { um melhor efeito anti-H. pylori. }\end{array}$ \\
\hline PubMed & 2019 & Koga et al. & $\begin{array}{l}\text { Probiotic L. gasseri strain (LG21) for the upper } \\
\text { gastrointestinal tract acting through improvement of } \\
\text { indigenous microbiota. }\end{array}$ & $\begin{array}{l}\text { L. gasseri parece eficazes no tratamento da dispepsia } \\
\text { funcional através da normalização da microbiota gás- } \\
\text { trica, principalmente via redução de Escherichia. }\end{array}$ \\
\hline PubMed & 2019 & Aiba et al. & $\begin{array}{l}\text { Synergistic effect of anti-Helicobacter pylori urease im- } \\
\text { munoglobulin Y from egg yolk of immunized hens and } \\
\text { Lactobacillus johnsonii No.1088 to inhibit the growth } \\
\text { of Helicobacter pylori in vitro and in vivo. }\end{array}$ & $\begin{array}{l}\text { L. johnsonii (J88) em combinação com a imunoglobuli- } \\
\text { na lgY anti- H. pylori pode ser uma abordagem promis- } \\
\text { sora para inibir H. pylori, sem riscos de surgimento de } \\
\text { resistência a antibióticos. }\end{array}$ \\
\hline Medline & 2019 & Poonyam et al. & $\begin{array}{l}\text { High effective of 14-day high-dose PPI-bismuth-con- } \\
\text { taining quadruple therapy with probiotics supplement } \\
\text { for Helicobacter pylori eradication: A double blinded- } \\
\text {-randomized placebo-controlled study. }\end{array}$ & $\begin{array}{l}\text { L. reuteri na terapia quádrupla em } 14 \text { dias com altas } \\
\text { doses de bismuto fornece alta taxa de cura da infecção } \\
\text { por H. pylori em pacientes tailandeses com dispepsia } \\
\text { não ulcerosa. A adição de probióticos também dimi- } \\
\text { nuiu os efeitos colaterais durante o tratamento. }\end{array}$ \\
\hline PubMed & 2019 & Yu et al. & $\begin{array}{l}\text { Efficacy of Lactobacillus-supplemented triple therapy } \\
\text { for H. pylori eradication: A meta- analysis of randomi- } \\
\text { zed controlled trials. }\end{array}$ & $\begin{array}{l}\text { As evidências sugerem que a suplementação de Lac- } \\
\text { tobacillus spp. durante o tratamento com terapia tripla } \\
\text { padrão para H. pylori melhorar significativamente as } \\
\text { taxas de erradicação e reduzir a incidência de distúr- } \\
\text { bios do paladar. }\end{array}$ \\
\hline PubMed & 2019 & Shi et al. & $\begin{array}{l}\text { Efficacy and safety of probiotics in eradicating Helico- } \\
\text { bacter pylori A network meta-analysis. }\end{array}$ & $\begin{array}{l}\text { Lactobacillus spp. teve melhor taxa de erradicação } \\
\text { comparado ao uso de múltiplas cepas ou outra espécie } \\
\text { de outros tipos. Houve menor uma redução nos efeitos } \\
\text { colaterais causados pelo tratamento quadruplo ou } \\
\text { triplo. }\end{array}$ \\
\hline Medline & 2019 & Chen et al. & $\begin{array}{l}\text { Probiotic Lactobacillus spp. act Against Helicobacter } \\
\text { pylori-induced Inflammation }\end{array}$ & $\begin{array}{l}\text { L. rhamnosus e L. acidophilus possuem atividade an- } \\
\text { timicrobiana contra o crescimento e a inflamação por } \\
\text { H. pylori. }\end{array}$ \\
\hline Medline & 2019 & Asgari et al. & $\begin{array}{l}\text { The Anti-Helicobacter pylori Effects of Lactobacillus } \\
\text { acidophilus, L. plantarum, and L. rhamnosus in Stoma- } \\
\text { ch Tissue of C57BL/6 Mice. }\end{array}$ & $\begin{array}{l}\text { L. acidophilus, L. plantarum, e L. rhamnosus podem ser } \\
\text { utilizados como complemento contra infecção por H. } \\
\text { pylori como suplementos juntamente com inibidores } \\
\text { da bomba de prótons, podendo ter efeitos mais be- } \\
\text { néficos na melhora da gastrite induzida por H. pylori. } \\
\text { Além disso, podem reduzir a resistência a antibióticos } \\
\text { comumente usados no tratamento de H. pylori. }\end{array}$ \\
\hline
\end{tabular}


Em relação ao idioma de publicação, os 16 artigos selecionados foram publicados em língua inglesa. Em relação ao ano de publicação, três foram publicados em 2015 (18\%), um, em 2016 (5\%), um, em 2017 (12\%), quatro, em 2018 (25\%), e sete, no ano de 2019 (40\%).

De acordo com a origem, quatro eram da China (34\%), dois, do Chile (12\%), dois, da Alemanha (12\%), dois, do Irã (12\%), os seis restantes eram dos seguintes países: Egito, Irlanda, Itália, Japão, Tailândia e Taiwan, com a parcela de $5 \%$ para cada.

Foram encontrados, em sete estudos, as funções de cepas de Lactobacilos na erradicação do H. pylori. Como sugeriram os autores García et al. ${ }^{15}$, a cepa probiótica $L$. fermentum foi eficaz na redução da adesão do patógeno a mucosa gástrica. Na mesma direção, os autores Ji et al. ${ }^{16}$ destacaram que a cepa L. acidophilus reparou a mucosa gástrica afetada pela colonização do H. pylori. Já o estudo de Asgari et al. ${ }^{18}$ afirmou que a cepa $L$. rhamnosus sintetiza bacteriocinas, mas que depende da despolarização do $\mathrm{H}$. pylori ocasionada pelo bismuto para que as bacteriocinas atinjam com sucesso o $\mathrm{H}$. pylori, além disso, apontaram a cura da gastrite nos camundongos infectados ${ }^{17}$.

Os autores Enany e Abdalla ${ }^{18}$ descreveram, em seu estudo, que a cepa L. casei imunitass inibiu a motilidade do $\mathrm{H}$. pylori de modo irreversivelmente por meio da alteração morfológica das células, causando a perda das flagelinas, FlaA e FlaB, proteínas que constituem o flagelo da bactéria ${ }^{18}$. Conforme os autores Koga et al. ${ }^{19}$, a cepa L. gasseri (LG21) possui efeito supressor na produção de IL-8, reduzindo assim a inflamação ocasionada pela presença do H. pylori ${ }^{19}$. Já o estudo de Holz et al. ${ }^{20}$ relatou que a cepa L. reuteri possui atividade de coagregação em que se liga as células que a $\mathrm{H}$. pylori se ligaria para colonização do epitélio gástrico ${ }^{20}$. Aiba et al. ${ }^{21}$ demonstraram que a cepa L. johnsonii (J88) destrói a estrutura celular do H. pylori, reduzindo a infecção.

As funções dos Lactobacilos como complemento ao tratamento de erradicação e o nome de cada uma das cepas que realiza tais funções podem ser vistas no Quadro 2.

Quadro 2. Funções dos Lactobacilos utilizados como complemento conforme a dados obtidos.

\begin{tabular}{|l|c|c|}
\hline Funções & Nome da cepa & Autores \\
\hline $\begin{array}{l}1 \text { Diminuição da adesão do } \\
\text { patógeno }\end{array}$ & L.fermentum & García et al. ${ }^{15}$ \\
\hline 2 Reparo da mucosa & L.acidophilus & Ji et al. ${ }^{16}$ \\
\hline 3 Sintetiza bacteriocinas & L. rhamnosus & Asgari et al. ${ }^{17}$ \\
\hline
\end{tabular}

\begin{tabular}{|l|c|c|}
\hline $\begin{array}{l}4 \text { Inibe a motilidade do } \\
\text { patógeno }\end{array}$ & L casei Imunitass & Enany e Abdalla ${ }^{18}$ \\
\hline 5 Supressão da inflamação & L. gasseri (LG21) & Koga et al. ${ }^{19}$ \\
\hline 6 Atividade de co-agregação. & L. reuteri & Holz et al.20 \\
\hline $\begin{array}{l}7 \text { Destrói estrutura celular do } \\
\text { H. pylori }\end{array}$ & L. johnsonii & Aiba et al.21 \\
\hline
\end{tabular}

De acordo com os sinais e sintomas causados pelo uso de antibióticos e bismuto, foram encontrados sete estudos tratando do tema. Lü et al. ${ }^{22}$ apontaram melhoras em: vômito, diarreia e constipação. Já os autore ${ }^{18}$ retrataram melhora em vômitos, distúrbios do paladar e náusea. O trabalho de Shi et al..$^{23}$ descreveu melhora em: vômito, distúrbio do paladar, diarreia, constipação e náusea. Poonyam et al. ${ }^{24}$ revelaram melhora nos sintomas de: vômito, distúrbios do paladar, distensão abdominal e náusea. Já os autores Yu et al. ${ }^{25}$ sugeriram apenas a melhora em distúrbios do paladar. Os autores Paoluzi et al. ${ }^{26}$ relataram melhora de distúrbios do paladar, diarreia e inchaço. $E$, finalmente, os autores Buckley et al. ${ }^{27}$ demonstraram melhora somente na constipação (Quadro 3).

Quadro 3. Sinais e Sintomas que apresentaram melhora com o uso de Lactobacilos concomitante ao tratamento conforme dados obtidos.

\begin{tabular}{|c|c|}
\hline $\begin{array}{l}\text { Distúrbios do paladar } \\
\text { (5 artigos) }\end{array}$ & $\begin{array}{c}\text { Enany; Abdalla }{ }^{18} \text {; Shi et al. }{ }^{23} \text {; Poonyam et al. }{ }^{24} \text {; Yu et } \\
\qquad \text { al. }{ }^{25} \text {; Paoluzi et al. }{ }^{26}\end{array}$ \\
\hline Vômito (4 artigos) & $\begin{array}{c}\text { Abdalla }{ }^{18} ; \text { Lü et al. }{ }^{22} ; \text { Enany; Shi et al. }{ }^{23} ; \\
\text { Poonyam et al. }{ }^{24}\end{array}$ \\
\hline Constipação (3 artigos) & Lü et al. ${ }^{22}$; Shi et al. ${ }^{23}$; Buckley et al. ${ }^{27}$ \\
\hline Diarreia (3 artigos) & Lü et al. ${ }^{22} ;$ Shi et al. ${ }^{23} ;$ Paoluzi et al. ${ }^{26}$ \\
\hline Náusea (3 artigos) & Enany; Abdalla ${ }^{18}$; Shi et al. ${ }^{23} ;$ Poonyam et al. ${ }^{24}$ \\
\hline $\begin{array}{l}\text { Distensão abdominal } \\
\text { (1 artigo) }\end{array}$ & Poonyam et al..$^{24}$ \\
\hline Inchaço (1 artigo) & Paoluzi et al. ${ }^{26}$ \\
\hline
\end{tabular}

\section{Discussão}

H. pylori é uma bactéria patogênica móvel, que coloniza o epitélio estomacal ${ }^{17}$, e dois genes estão relatados aos principais fatores de virulência para induzir a patogênese, a citotoxina associada ao gene A ( ( $a g A)$ e a citotoxina de vacuolização $A(\operatorname{Vac} A)$. CagA é introduzida em células hospedeiras por sistema de secreção tipo IV, a translocação de CagA nas células hospedeiras induz a ativação e produção de interleucina 8 (IL-8), quimiocina responsável pela ativação dos neutrófilos. VacA é secretada por H. pylori e interrompe as funções mitocondriais das células hospedeiras, induzindo a apoptose. Ocorre também o desequilíbrio na somatostatina que induz a secreção anormal de ácido gástrico após 
infecção22,28. A infecção causa inflamação e dano tissular, podendo progredir para patologias graves, como ulcera péptica ou adenocarcinoma gástrico ${ }^{15,17,28}$.

A erradicação da infecção, por $H$. pylori, pode reduzir amplamente o risco de lesões pré-cancerosas e câncer gástrico ${ }^{16}$, terapias com uso do mesmo antibiótico em altas doses, ou com uso prolongado, podem levar ao desequilíbrio da microbiota intestinal, causando e aumentando as reações adversas ${ }^{25}$. Além disso, existem alguns obstáculos em relação à antibioticoterapia, como: acesso limitado deste ao lúmen do estomago, sendo pouco secretado na mucosa gástrica, ou por atingirem o estomago em baixa concentração ${ }^{18}$. Adicionalmente, há reações adversas relatadas constantemente pelos pacientes, tais como: náusea, vômito, diarreia, constipação, perda de apetite, distensão abdominal e distúrbios do paladar ${ }^{23,24}$, causadas pelos esquemas de erradicação com antibióticos, como: Amoxicilina, Tetraciclina, Metronidazol, Claritromicina ${ }^{17}$, que podem ser aplicados em regime triplo composto por um inibidor de bomba de prótons mais dois antibiótico ${ }^{22,23}$. E o regime quádruplo, recomendado para o aumento da sensibilidade em casos de resistência ${ }^{23}$, podendo ser recomendado em tratamento de primeira linha ${ }^{18,28}$; é composto por um inibidor da bomba de prótons, bismuto coloidal e dois antibióticos $16,22,24$.

Os probióticos sugiram como uma nova opção terapêutica para condições infecciosas ${ }^{17}$. Eles podem ser utilizados como monoterapia ou concomitante ao tratamento convencional ${ }^{27}$, desempenhando papel auxiliar contra infecção por H. pylori. Os microrganismos devem ter algumas características para serem enquadrados como probióticos, além da sobrevivência e viabilidade quando forem consumidos em alimentos ${ }^{29}$. Estas características são: possuir aspectos funcionais e de segurança, não ser patogênicos, produzir substâncias antibacterianas para competir com o patógeno, ser tolerante ao ácido gástrico e sais biliares, colonizar o epitélio gastrintestinal, não conter genes transmissíveis de resistência a antibióticos, possuir a capacidade de modulação imunológica hospedeira ou inibição de toxinas e outros componentes tóxicos, como aminas biogênicas nocivas ${ }^{15,26}$. Porém, nem todos os tipos de probióticos são eficazes ${ }^{25}$; entre os tipos eficazes na erradicação de $H$. pylori em conjunto ao tratamento convencional, estão as cepas de probióticos produtores de ácido lático ${ }^{21}$, já que estes reduzem a atividade da urease, mediada pelos ácidos graxos de cadeia curta ${ }^{23}$.

A microbiota gastrintestinal é composta por alguns microrganismos, entre eles, estão os Lactobacilos presentes no epitélio gástrico ${ }^{16,26}$. Os Lactobacilos são bactérias gram-positivas, consideradas probióticas por exercerem efeitos benéficos ao trato gastrintestinal ${ }^{15}$, as estirpes tem sido usadas em profilaxia ou na terapia da infecção por $\mathrm{H}$. pylori. As cepas de Lactobacilos produzem bacteriocinas que exercem efeitos inibitórios sobre $H$. pylori, já que, além de secretar metabolitos que inibem a atividade de urease de $H$. pylori, também promovem competição no local de adesão, estabilização da barreira mucos $\mathrm{a}^{18}$ e produzem ácido lático, ácido acético, peróxido de hidrogênio e reuterina, que possuem propriedades antibióticas ${ }^{24}$. Também regula a resposta imune, facilitando reduções na expressão inflamatória, por meio das vias de sinalização dos fatores de transcrição Nf$k B$, e promovem a anti-inflamação por meio do supressor da ativação da sinalização de citocinas ${ }^{22}$. Por esses fatores, os Lactobacilos também funcionam como reguladores da microbiota gastrintestinal, além de estimular a proliferação de outras bactérias benéficas ${ }^{23}$. Existem cepas que se ligam as células que são colonizadas por $H$. pylori no estomago como a $L$. reuteri e $L$. fermentum ${ }^{20}$, cepas que possuem maior taxa de erradicação como a L. rhamnosus, L. acidophilus e $L$. plantarum ${ }^{30}$ e aquelas cepas que agem melhor em conjunto com outros agentes, como a L. johnsonii em conjunto com a imunoglobulina $Y$, que age contra proteínas específicas, como a urease ${ }^{21}$. Além disso, existem as que são encapsuladas por carragenina (L. fermentum), um aditivo que possui ácido sulfatado que se liga a membrana biológica, competindo com os locais de ligação de $H$. pylori ${ }^{29}$.

Em diversos estudos ${ }^{15,19,21,30}$, os resultados foram promissores em relação ao uso de Lactobacilos contra a infecção por H. pylori, juntamente com o tratamento de erradicação. E ainda há como, ponto positivo, para o uso de cepas de Lactobacilos, a redução das reações causados pela terapia com antibióticos e bismuto, que muitas vezes impedem a adesão ao tratamento, como: paladar amargo, vômitos e náusea ${ }^{23,24}$. Alguns estudos demonstraram a melhora de patologias causadas pela infecção da H. pylori, como gastrite e úlcera péptica ${ }^{17,30}$. Embora, alguns estudos demonstraram que a redução de sinais e sintomas tenham sido ligeiramente menor em pacientes tratados com as cepas probióticas de Lactobacilo ${ }^{26}$ ou apresentado melhora apenas em um único tipo de efeito, o paladar amargo ${ }^{25}$. Portanto, são necessários que estudos futuros destaquem os sinais e sintomas como assunto principal, já que há divergências entre os estudos.

\section{Conclusão}

Com base nos achados do presente estudo, conclui-se que as cepas probióticas de Lactobacilos: L. fermentum, L. acidophilus, L. rhamnosus, L. casei imunitass, L. gasseri (LG21), L. reuteri e L. johnsonii (J88) são eficazes como complemento ao tratamento 
de erradicação do Helicobacter pylori, tanto em regimes de terapia tripla ou quádrupla. Em relação aos achados de redução nas reações adversas causadas pelo tratamento de erradicação, entende-se que há redução de alguns sintomas, como: distúrbios do paladar, vômito, náusea, diarreia, constipação, distensão abdominal e inchaço, inclusive melhoras em patologias causadas pelo H. pylori, como gastrite e úlcera péptica. Novos estudos devem ser realizados na tentativa de ampliar a avaliação do uso de lactobacilos no auxílio ao tratamento da $H$. pylori e no abrandamento de reações adversas comuns ao este tratamento.

\section{Referências}

1. Safavi M, Sabouriam R, Foroumadi A. Treatment of Helicobacter pylori infection: Current and future insights. World J Clin Cases. 2016;4(1):5-19.

2. Ruggiero P. Use of probiotics in the fight against Helicobacter pylori. World J Gastrointest Pathophysiol. 2014;5(4):384.

3. Kafshdooz T, Akbarzadeh A, Majdi Seghinsara A, Pourhassan M, Nasrabadi HT, Milani M. Role of probiotics in managing of Helicobacter pylori infection: a review. Drug Res (Stuttg). 2017;67(2):88-93.

4. Kuiper EJ. Helicobacter pylori and the risk and management of associated diseases : gastritis, ulcer disease, atrophic gastritis and gastric cancer. Aliment Pharmacol Ther. 1997;11(1):71-88.

5. Malfertheiner P, Megraud F, O'Morain C, Bazzoli F, ElOmar E, Graham D, et al. Current concepts in the management of Helicobacter pylori infection: The maastricht III consensus report. Gut. 2007;56(6):772-81.

6. Homan M, Orel R. Are probiotics useful in Helicobacter pylori eradication? World J Gastroenterol. 2015;21(37):10644-53.

7. Henry A, Batey RG. Enhancing compliance not a prerequisite for effective eradication of Helicobacter pylori: The HelP study. Am J Gastroenterol. 1999;94(3):811-5.

8. Vieira LQ, Penna FJ, Péret Filho LA, Nicoli JR. Uso de probióticos na prevenção e tratamento de infecções e inflamações gastrintestinais. Rev Med Minas Gerais. 2007;17(1/2):45-53.

9. Food and Agriculture Organization/World Health Organization. Health and nutritional properties of probiotics in food including powder milk with live lactic acid bacteria. Prevention. 2001;5(1):1-34.

10. Guarner F. Probiotics. Int J Food Microbiol. 1997;39:237-8.

11. Lesbros-Pantoflickov D, Corthesy-Theulaz I, L.
Blum A. Helicobacter pylori and probiotics. J Nutr. 2007;61(3):273-7.

12. Goderska K, Agudo Pena S, Alarcon T. Helicobacter pylori treatment: antibiotics or probiotics. 2018;102(1):1-7.

13. Souza MT, Silva MD, Carvalho R. Revisão integrativa : o que é e como fazer. Einstein. 2010;8:102-6.

14. Botelho LLR, Cunha CCA, Macedo M. O método da revisão integrativa nos estudos organizacionais. Gestão e Soc. 2011;5(11):121-35.

15. García A, Navarro K, Sanhueza E, Pineda S, Pastene E, Quezada M, et al. Characterization of Lactobacillus fermentum UCO-979C, a probiotic strain with a potent anti-Helicobacter pylori activity. Elsevier BV. 2017;25:75-83.

16. Ji W, Chen WQ, Tian X. Efficacy of compound Lactobacillus acidophilus tablets combined with quadruple therapy for Helicobacter pylori eradication and its correlation with $\mathrm{pH}$ value in the stomach: a study protocol of a randomised, assessor-blinded, singlecentre study. BMJ Open. 2018;8(10):1-6.

17. Asgari B, Kermanian F, Derakhshan N, Asna-Ashari M, Sadat ZRN, Yaslianifard S. Honey-derived lactobacillus rhamnosus alleviates Helicobacter pylori-induced gastro-intestinal infection and gastric inflammation in C57BL/6 mice: an immuno-histologic study. Arq Gastroenterol. 2018;55(3):279-82.

18. Enany $S$, Abdalla $S$. In vitro antagonistic activity of lactobacillus casei against Helicobacter pylori. Brazilian J Microbiol. 2015;46(4):1201-6.

19. Koga Y, Ohtsu T, Kimura K, Asami Y. Probiotic L. gasseri strain (LG21) for the upper gastrointestinal tract acting through improvement of indigenous microbiota. BMJ Open Gastroenterol. 2019;6(1):1-8.

20. Holz C, Busjahn A, Mehling H, Arya S, Boettner M, Habibi $\mathrm{H}$, et al. Significant reduction in Helicobacter pylori load in humans with non-viable lactobacillus reuteri DSM17648: a pilot study. Probiotics Antimicrob Proteins. 2015;7(2):91-100.

21. Aiba Y, Umeda K, Rahman S, Nguyen S V., Komatsu Y. Synergistic effect of anti-Helicobacter pylori urease immunoglobulin $Y$ from egg yolk of immunized hens and Lactobacillus johnsonii No.1088 to inhibit the growth of Helicobacter pylori in vitro and in vivo. Elsevier. 2019;37(23):3106-12.

22. Lü M, Yu S, Deng J, Yan Q, Yang C, Xia G, et al. Efficacy of probiotic supplementation therapy for Helicobacter pylori eradication: A meta-analysis of randomized 
controlled trials. PLoS One. 2016;11(10):1-26.

23. Shi X, Zhang J, Mo L, Shi J, Qin M, Huang X. Efficacy and safety of probiotics in eradicating Helicobacter pylori: a network meta-analysis. Medicine (Baltimore). 2019;98(15):1-14.

24. Poonyam P, Chotivitayatarakorn P, Vilaichone RK. High effective of 14-day high-dose PPI-bismuth-containing quadruple therapy with probiotics supplement for Helicobacter pylori eradication: a double blindedrandomized placebo-controlled study. Asian Pacific J Cancer Prev. 2019;20(9):2859-64.

25. Yu M, Zhang R, Ni P, Chen S, Duan G. Efficacy of Lactobacillus-supplemented triple therapy for $\mathrm{H}$. Pylori eradication: A meta-analysis of randomized controlled trials. PLoS One. 2019;14(10):1-16.

26. Paoluzi OA, Del Vecchio Blanco G, Visconti E, Coppola $M$, Fontana $C$, Favaro $M$, et al. Low efficacy of levofloxacin-doxycycline-based third-line triple therapy for Helicobacter pylori eradication in Italy. World J Gastroenterol. 2015;21(21):6698-705.

27. Buckley M, Lacey S, Doolan A, Goodbody E, Seamans $\mathrm{K}$. The effect of Lactobacillus reuteri supplementation in Helicobacter pylori infection: a placebo-controlled, single-blind study. 2018;4(1):1-8.

28. Chen Y-H, Tsai W-H, Wu H-Y, Chen C-Y, Yeh W-L, Chen $\mathrm{Y}-\mathrm{H}$, et al. Probiotic Lactobacillus spp. act against Helicobacter pylori-induced inflammation. J Clin Med. 2019;8(1):1-16.

29. Gutiérrez-Zamorano C, González-Ávila M, Díaz-Blas G, Smith CT, González-Correa C, García-Cancino A. Increased anti-Helicobacter pylori effect of the probiotic Lactobacillus fermentum UCO-979C strain encapsulated in carrageenan evaluated in gastric simulations under fasting conditions. Elsevier. 2018;121:812-6.

30. Asgari B, Kermanian F, Hedayat Yaghoobi M, Vaezi A, Soleimanifar F, Yaslianifard S. The Anti- Helicobacter pylori Effects of Lactobacillus acidophilus, L. plantarum, and L. rhamnosus in Stomach Tissue of C57BL/6 Mice. Visc Med. 2019;36(2):1-7. 